\title{
Barriers, Bridges, and the Trolls under the Bridge: Issues in Human Factors Education for Engineers and Others
}

\author{
William S. Helton, Michele H. Miller, and Robert Pastel \\ Michigan Technological University \\ Houghton, Michigan
}

\begin{abstract}
Human Factors (HF) is the scientific discipline concerned with the interactions among humans and built systems. HF requires the knowledge of both human experts (psychology) and machine experts (for example, computer science and mechanical engineering). In this paper, we will present our observations of teaching HF from the perspective of a psychologist, a mechanical engineer, and a computer scientist. We will discuss our observations in terms of barriers, bridges and the trolls under the bridge. Barriers are the substantive disciplinary differences that make teaching such an interdisciplinary field challenging. Bridges are the shared communalities that make HF such an easy way to get students to consider multiple perspectives and to think "outside the box." The trolls are the bureaucratic-institutional barriers that make teaching such an interdisciplinary field potentially challenging, and like trolls, they may be imaginary.
\end{abstract}

\section{Human Factors}

Human Factors (HF), or ergonomics, is the scientific discipline concerned with the interactions among humans and built systems. Human operators are often considered to be the critical contributors to lapses in overall system safety. In medicine, for example, human errors have been attributed as the cause of up to 98,000 preventable patient deaths a year (Dumas, 1999). When there are lapses in homeland security, humans, likewise, usually get the blame. On September 11, 2001, nineteen terrorists eluded airport security and managed to hijack four jet liners. Using these aircraft as weapons they were able to inflict incalculable damage both in terms of human life and property loss. The immediate reaction was the passing of the Aviation and Transportation Security Act on November 19, 2001, thus creating the Transportation Security Administration (TSA) and making them responsible for day-to-day security screening operations for passenger air transportation. The TSA was commissioned to train and select new security personnel, presumably, because the errors of 9/11 must have been due to careless human screeners.

The wide-spread popularity of science fiction films and books undoubtedly leads people, including engineering and computer science students, to believe that there are foolproof technological fixes to problems of human error. If only there were adequate funding, critical systems in security and medicine could be fully automated. This is, however, a mistaken notion. Despite our desire for automated, faultless systems, our current engineering knowledge is not capable of this level of sophistication. Substantial funding 
has been allocated to research on machine intelligence, pattern-recognition technologies, and expert systems, but they are still in their infancy. There is only one alternative for many complex systems: to include human operators.

Humans are excellent pattern recognizers and, unlike current automated systems, are immensely flexible. People do, however, have limitations. HF is the interdisciplinary field of study concerned with understanding these limitations, and requires the knowledge of both human experts (psychology) and machine experts (computer science and mechanical engineering). In this paper, we will present our observations of teaching HF from the perspective of a psychologist, a mechanical engineer, and a computer scientist. We will discuss our observations in terms of barriers, bridges and the trolls under the bridge.

- Barriers - real disciplinary barriers that make teaching such an interdisciplinary field challenging

- Bridges - things that make HF such an easy way to get students to consider multiple perspectives and to think "outside the box."

- Trolls Under the Bridge - bureaucratic/institutional barriers

Prior to our discussion of these three items we will briefly explain how HF is currently taught at our institution in our respective disciplines: psychology, mechanical engineering and computer science.

HF courses in psychology are typically taught either as an engineering psychology course or a human performance course. The former is more about systems broadly construed and the later is more directly focused on understanding the limitation of humans. At Michigan Tech, we teach PSY4120 Human Factors Psychology and PSY4100 Environmental Psychology on an alternate year schedule. The Human Factors psychology course introduces students, regardless of major, to the basic psychological concepts critical to the proper design of human-machine systems. Although there is some discussion of design, the focus is more directed on understanding the role of the human operator in a system. We have, however, in the past taken on design projects, including one that led to published work (Helton et al., in press). The environmental psychology course is broadly about the role of humans in environmental systems, but has a strong emphasis on how environmental variables, such as noise, thermal stress, and lighting, affect human performance and on macro-ergonomics (building design and urban planning).

HF courses in mechanical engineering have a strong connection to product design. Michigan Tech offers a technical elective MEEM 4990/5990 Human Factors in Engineering that is open to seniors and graduate students. The course presents the physical and psychological capabilities and limitations of humans. We look at bad product and system designs. We explore the reasons a product may be difficult to use or the causes behind a system safety failure. The course presents tools and techniques for improving the usability of products and systems. Often mechanical engineers will attempt 
to "idiot proof" their designs, but that is the extent of their consideration of human factors. An underlying goal of the course is to promote a more empathic view of the user.

Human factors courses in computer science (CS) are taught as either user interface (UI) centered design and testing or human-computer interaction (HCI), or graphical user interface (GUI) implementation courses (Leventhal et al., 2004). All flavors of the course (which we will call as a group HCI) introduce students to the realization that computers and application programs are used by people to achieve goals, either to accomplish a specific task or for entertainment. The course does not necessarily teach programming, or about the computing machine or system. In the hope to ease CS students into HF concepts, the HCI course is taught in the CS curriculum as a project based implementation and user centered design course, CS4760. Students design and implement UIs of their choosing (Pastel, 2005). The CS course also requires students to identify user goals and tasks to achieve their goals. CS students take the HCI course in their junior or senior year, so they should be academically well prepared. HCI is one of the few system engineering courses taught in the CS curriculum.

\section{Barriers}

Barriers are the substantive disciplinary differences that make teaching such an interdisciplinary field challenging, such as a differences in vocabulary-language, epistemology-methods, and disciplinary histories. Because HF is the boundary between the human sciences, such as psychology, and the machine sciences, such as engineering and computer science, there are real differences between these two areas that make teaching HF challenging. If these barriers are left unaddressed, there may be a tendency to revert to teaching a course not about HF, but another course fixated on issues only of interest to the home discipline, such as human cognition, bio-mechanics, or programming. These topics although important are already covered by other courses and in the context of HF miss the point: HF is the boundary.

Philosophers and historians of science and technology have debated and continue to debate the differences between the human and mechanical (or natural) sciences (Boyd, Gasper, \& Trout, 1991); the issue is, needless to say, immensely complex. In order to simplify our discussion we will use a classification scheme inspired by the work of Hacking (1999). Disciplines differ in regards to both their ontology and their epistemology. Ontology, the study of being, refers to the kinds of objects studied. The natural and mechanical sciences focus mostly on natural kinds where as the human sciences focus mostly on interactive kinds. Natural kinds are objects whose activities are not affected by human classification. Interactive kinds are objects whose activities may change due to human classification. For example, sedimentary rocks are unaffected by their classification by earth scientists as sedimentary. The rocks' properties are naturally what they are and are not affected by what the scientist chooses to call them. This is not the case with humans. The mentally ill, for example, are affected by how scientists and others classify them. A person who hears voices could be classified as holy or schizoid. This difference in classification undoubtedly will affect how the person acts. Humans are interactive kinds. 
Sciences also differ in regards to their epistemologies. Sciences tend to rely on description and observation, or on experimentation and manipulation. The various combinations of ontology and epistemology are displayed in Figure 1. There are natural or mechanical sciences focused on natural kinds but with an observational epistemology - astronomy is an example. There are also natural or mechanical sciences with an experimental epistemology - bench or laboratory physics is an example. Like wise there are human sciences which focus on interactive kinds with an experimental epistemology cognitive psychology is an example - or an observation epistemology - cultural anthropology is an example.

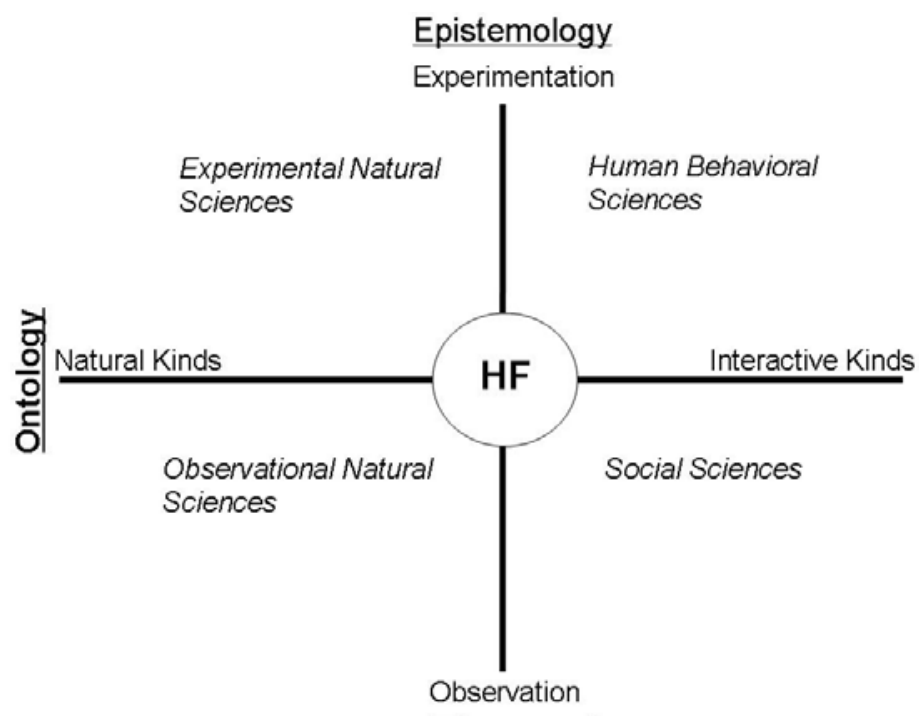

Figure 1

Furthermore, the sciences differ in the level of precision of measurement that can be exerted and the use of quantification. This could be visualized as a third dimension added to Figure 1. Economics, for example, has very easy and precise measurement (money is numbers) and is extremely quantitative, rivaling physics in the level of mathematical abstraction and detail. On the other hand, cultural anthropology is not very precise and the level of quantification is very low; it is primarily a qualitative discipline. Both economics and cultural anthropology are observational human sciences focused primarily on interactive kinds. The same is true in the natural-mechanical sciences. Both astronomy and paleontology are observational sciences focused on natural kinds, but whereas astronomy is extremely quantitative, paleontology is more qualitative. All of them are equally science, despite disparaging remarks made sometimes by members of some disciplines about other disciplines.

These ontological and epistemological differences can prove challenging for HF instructors, because, as is pictured in Figure 1, HF is central to all the sciences or is the convergence point of the human and mechanical (natural) sciences. Engineers and computer scientists are more comfortable with quantification and simplified systems where quantification is easy. Psychologists, and other human scientists, are more comfortable with complexity and are actually uncomfortable with simplification, because 
their subjects are fundamentally interactive or in other words, tricky to study. Research (Smyth, 2001) has demonstrated that psychologists overly qualify knowledge claims and are generally hesitant in regards to the field's “facts.” Popular works (Horgan, 1999) often reinforce the myth that psychologists do not understand humans better than lay people. When actually tested (Bailey, 1993), designers with a psychology background out perform their non-psychology peers and build better systems. Psychologists' use of quantification, such as statistical hypothesis testing, is usually performed in a rich narrative context: qualitative story-telling. In regards to design, psychologists sometimes unnecessarily complicate a problem and are overly hesitant to make specific design recommendations. Psychologists' constant “well it depends” perspective can stall design secessions. This can prove very frustrating for engineers. On the other hand, engineers sometimes overly simplify a system and seek quantification where none is available.

The HF instructor, regardless of home discipline, needs to realize their own discipline's limited orientation and be willing to assume the perspective of the other disciplines involved. For example, engineering instructors need to be able to abandon the certainty of their own discipline and take on the role of a skeptical "it depends" psychologist. Likewise, psychology instructors need to be able to abandon the complexity and hesitancy of their own discipline and deploy psychological knowledge in a simplified context to get the design job done.

These disciplinary differences lead to issues in regards to shared terminology, expectations, research tools and such, but our belief is that the primary barrier can be somewhat mitigated by explaining to students/instructors these real ontologicalepistemological differences. The remaining issues, like a lack of a shared vocabulary, will resolve once students understand they are not in Kansas anymore: the perspective of their own discipline no longer cuts it and they have to mentally stretch-out. Instructors need to be aware that this mental stretching process is uncomfortable for many students, but not to succumb to complaints by students, lest they miss the whole point and revert to teaching a course in human cognition, bio-mechanics, or programming.

HF is about system engineering. System engineering is difficult to teach because students often do not have enough experience or maturity to intuitively understand the individual components and view the components interacting as a system. CS students, for example, have a detailed understand of computer systems, but they have difficulty generalizing what they know about the computer system to human systems. CS students have difficulty imagining an end user unlike themselves, and design interfaces for users similar to themselves. The students often neglect identifying the users, their needs and capabilities. The students do better at identifying user tasks, but then the tasks have been defined by their choice of projects. The students should also test and evaluate their UIs, but they have no experience with user testing and believe that testing is debugging a program. Consequently, the students can not objectively evaluate their interfaces. Similar problems emerge in each discipline. HF instructors need to be patient. 


\section{Bridges}

Bridges are the shared communalities that make HF such an easy way to get students to consider multiple perspectives and to think "outside the box.” Regardless of discipline, for example, HF practitioners share common interests in subject matter and an applied problem-focused orientation. Because the content of HF courses relates to everyday life, the material is easy to relate to regardless of the students' home disciplines. HF courses also deal with dramatic events (accidents and disasters) and students have a shared curiosity and interest in figuring out what made the event happen. HF, simply, is cool.

Frequently what are initially perceived as barriers can become bridges. The detailed training and knowledge that CS students, for example, have of the computer system enables them to recognize the difference between a system error and a usability problem. Their detailed knowledge of the computer system also empowers them to develop new devices and interaction techniques. All CS students become bored with the mundane practice of programming without a purpose that they experience in most of their courses and appreciate programming with a purpose that they experience in the HCI course. Psychology students also thrill at the idea of finally being able to deploy what they have learned in other courses in the real world. They feel pride that they can also make good design contributions, despite lacking formal training in the mechanical sciences.

Regardless of discipline, all students are human; they understand the foibles of being human, even if they have a perspective biased by their training. HF is interesting because it is about us and can make a real difference in the world. Many students feel good knowing they can make the world a better place. The rise in service learning in the United States attests to that. HF can be service learning, as students take on projects for their local community. The HF instructor needs to be enthusiastic about the role HF plays in the real world.

\section{Trolls}

The trolls are the bureaucratic-institutional barriers that make teaching such an interdisciplinary field challenging, and like trolls, they may be imaginary. Trolls are horrible monsters of Scandinavian mythology and fairytales; fear of trolls could keep people from trying new things or visiting new places. They were often depicted as living in places where travel would normally be possible; for example, in the Norwegian tale of Three Billy Goats Gruff, there is a fearsome troll who lives under a bridge. Travelers fear being eaten by the trolls lurking under the bridge and this fear prevents them from venturing to the other, perhaps, more exciting side. Trolls, however, are mythological. They exist only in one's imagination. Perhaps, institutional barriers to interdisciplinary work, such as HF, are trolls, e.g. scary fairytales to halt adventurers.

Some of the trolls may include: disciplinary colleagues who do not see the value in an HF course; the tendency of HF courses to stand on their own rather than be a required integrated part of the discipline's curriculum; difficulties in finding a suitable text book; team teaching complications; and in engineering, the possibility that a cross-listed course 
would raise flags about counting the course as a "technical elective." Although there is no easy way to gather data on this, our personal experiences suggest most of these difficulties are based on the perceptions of people in the home disciplines. The trolls are real; they really do exist in people's heads. But they are not self-existing issues like barriers. Most of the trolls are fears that HF instructors have of their home discipline colleagues rejecting them and folk-tales that home discipline colleagues have about the disasters of interdisciplinary work.

Generally fellow department members are not systems engineers. They would like to compartmentalize the subject matter and disciplines, and thus the tenure process is not geared for interdisciplinary researchers. Their list of acceptable journals and conferences for publications can be short, and they are reluctant to accept publications outside traditional areas of research. Although funding sources, such as the National Science Foundation, National Institute of Health and Department of Defense, speak as if to encourage interdisciplinary studies, their funding amounts for typical small projects is not sufficient to support more than one investigator and a couple of students. The referees judging the proposals do not have the breath of knowledge nor the patience for the creative insight into complex systems that are required for understanding system engineering. These are at least tales that are told to HF adventurers: "do not be interdisciplinary; it will kill your career.” There may be a kernel of truth to these folk tales; like Voodoo death, what people believe can have a real impact on them.

The simple fact, however, is that most real problems cannot be solved by one discipline. Funding sources, such as the National Science Foundation, encourage interdisciplinary work because it is necessary, and the pressure to be interdisciplinary is only going to increase with time. Companies are learning that people won't buy products that only computer scientists and engineers can understand and use. They will fail to be competitive if they do not get on the HF bandwagon. Eventually HF training will be a job requirement for engineers and technologists. Training in HF leads to better designs (Bailey, 1993) and in the global competitive market, money trumps trolls. HF instructors need to be aware of the trolls, but keep in mind they are probably only fairy tales. The only acceptable course of action for the HF instructor is to be brave.

\section{Conclusion}

HF is liberating and crucially important. Systems engineers are not inhibited and can choose to study any field. By its very nature, system engineering is constantly emerging. Once a system is perfected the interdisciplinary researcher can study the challenges in another field. We are never alone; rather we are always working with other scientists and engineers. There are real barriers to teaching HF, but the bridges make it doable. The trolls do exist in other people's heads. The best course of action for the HF instructor is to be patient in regards to the barriers, enthusiastic in regards to the bridges, brave in regards to the trolls and to constantly seek out like-minded colleagues in other disciplines. HF is an intellectual adventure, with many challenges and even more rewards. 


\section{References}

Bailey, G. (1993). Iterative methodology and designer training in human-computer interface design. ACM Proceedings INTERCHI' 93, 198-205.

Boyd, R., Gasper, P., \& Trout J.D. (Eds.) (1991). The philosophy of science. Cambridge, MA: MIT Press.

Dumas, L.J. (1999). Lethal arrogance: human fallibility and dangerous technologies. New York: St. Martin's Press.

Hacking, I. (1999). The social construction of what? Cambridge, MA: Harvard University Press.

Helton, W.S., Begoske, S., Pastel, R., \& Tan, J. (in press). Case study in canine-human factors: a remote scent sampler for landmine detection. Proceedings of the Human Factors and Ergonomics Society.

Horgan, J. (1999). The undiscovered mind: how the human brain defies replication, medication, and explanation. New York: Free Press.

Leventhal, L. M., Barnes, J., and Chao, J. (2004). Term project user interface specifications in a usability engineering course: challenges and suggestions. ACM Proceedings SIGCSE'04, 41-45.

Pastel, R. (2005). Integrating science and research in a HCI design course. ACM Proceedings SIGCSE'05, 31-35,

Smyth, M.M. (2001). Certainty and uncertainty sciences: marking the boundaries of psychology in introductory textbooks. Social Studies of Science, 31, 389-416.

\section{Author Biographies}

William S. Helton is currently an assistant professor of psychology in Michigan Technological University's Department of Cognitive and Learning Sciences. He teaches courses in Human Factors and Environmental Psychology. His research focuses on attention and skill development.

Michele H. Miller is an associate professor in the Mechanical Engineering-Engineering Mechanics department at Michigan Tech. In addition to teaching Human Factors in Engineering, Dr. Miller teaches courses on manufacturing processes and controls. Her primary research areas are precision manufacturing and microsystems.

Robert Pastel is currently an assistant professor in Michigan Technological University’s Computer Science Department. He teaches courses in Human Computer Interaction, Data Structures and Algorithms. His research interest is in developing quantitative measures in $\mathrm{HCI}$, and advancing human-computer interfaces beyond the GUI. 